\title{
Retratamiento endodóntico en pieza dental anterior con reabsorción radicular interna. Reporte de un caso
}

\section{Endodontic retreatment in the anterior tooth with internal root resorption. Case report}

\author{
Zambrano- Torres Miriam ${ }^{1}$,Briones- Cando Natali $^{2}$, Loyola-Arias Maria ${ }^{3}$, Moscoso- Abad Elizabeth $^{4}$ \\ ${ }^{1}$ Rotante de Investigación en la Universidad Católica de Cuenca, Ecuador. Odontóloga de práctica privada. \\ ${ }^{2}$ Rotante de Investigación en la Universidad Católica de Cuenca. Estudiante de pregrado de la Universidad Católica de \\ Cuenca. Cuenca, Ecuador. \\ ${ }^{3}$ Especialista en Endodoncia, Endodoncista de práctica privada. Loja, Ecuador. \\ ${ }^{4}$ Docente Especialista en Endodoncia. Universidad Católica de Cuenca. Cuenca, Ecuador. \\ *kari_42z@hotmail.com
}

\begin{abstract}
Resumen
La apariencia facial en la actualidad es considerada un factor importante en cuanto a la relación social del paciente, por lo que el estado de los dientes anteriores representa una prioridad de atención para los odontólogos. Es así que en el área de endodoncia es una prioridad la elección adecuada de las técnicas, como también de los instrumentos a utilizarse en los tratamientos, brindando así la posibilidad de manejar adecuadamente patologías de alta complejidad como los diferentes tipos de reabsorción radicular; con la finalidad de preservar la estructura dentaria y promover la protección del equilibrio a nivel del sistema estomatognático. La reabsorción radicular interna es una condición poco frecuente, que lleva a la pérdida progresiva de tejido dental como consecuencia de una actividad celular clástica anormal. Este reporte presenta ambas condiciones mencionadas, lo cual lo convierte en un caso de especial interés para la comunidad odontológica, el retratamiento en estos casos es complejo y requiere la utilización de instrumental específico y de técnicas determinadas para la desobturación, limpieza, conformación y obturación del conducto radicular.
\end{abstract}

Palabras clave: Reabsorción radicular interna;reabsorción dental ;retratamiento;endodoncia;conducto radicular..

\begin{abstract}
The facial appearance is now considered an important factor in the social relationship of the patient, so the condition of the anterior teeth represents a priority of attention for dentists. Therefore, in the area of endodontics, the adequate choice of techniques and instruments to be used in treatments is a priority, thus providing the possibility of adequately handling highly complex pathologies such as the different types of root resorption, with the purpose of preserving the dental structure and promoting the protection of the balance at the level of the stomatognathic system. Internal root resorption is a rare condition, which leads to the progressive loss of dental tissue as a consequence of abnormal clastic cell activity. This report presents both conditions mentioned, which makes it a case of special interest for the dental community. The retreatment in these cases is complex and requires the use of specific instruments and techniques for removal of root canal filling material, cleaning, shaping and obturation of the root canal.
\end{abstract}

Key words: Internal root resorption;tooth resorption;retreatment;endodontic;root canal..

\section{INTRODUCCIÓN}

Llevar a cabo un retratamiento endodóntico de una pieza dental se considera un reto, sin embargo, la presencia de una reabsorción radicular aumenta aún más la complejidad del tratamiento. La reabsorción radicular interna es una condición poco común, estimándose con una prevalencia del 0.01 al $1 \%$ en la cual encontramos una actividad celular clástica anormal que llevará a la pérdida progresiva de tejido dental. ${ }^{1}$ Su etiología no está determinada por completo, pero se pre- sume que la eliminación de predentina y de la capa externa sub odontoblástica deja expuesta la superficie de dentina mineralizada, permitiendo así la adherencia de odontoclastos que a su vez da paso a la iniciación de la reabsorción. ${ }^{2}$ Varios factores podrían causar la eliminación de estas barreras de defensa entre ellos se encuentran la caries dental, traumatismos, calor excesivo producido por procedimientos restauradores sin irrigación, tratamientos de ortodoncia, fisuras dentales, cambios distróficos idiopáticos en la pulpa e incluso se ha 
relacionado la presencia del Virus Herpes Zoster como desencadenante de esta condición. ${ }^{2,3}$

Para que la reabsorción radicular interna se desarrolle el tejido pulpar coronal a la lesión debe encontrarse necrótico e infectado; esta condición favorecerá la llegada de células y factores de inflamación, por otro lado, el tejido pulpar apical a la lesión debe encontrarse vital para suministrar sangre, células clásticas y nutrientes que aseguran su progresión., ${ }^{4,5}$

El diagnóstico de una reabsorción radicular interna suele ocurrir como un hallazgo radiográfico, ya que el paciente generalmente se encuentra asintomático en la mayoría de los casos. Sin embargo, las manifestaciones clínicas dependen del estado histológico del tejido pulpar, el lugar y la magnitud de la reabsorción. Ocasionalmente la contaminación bacteriana del tejido pulpar vital desencadena una respuesta aguda con sintomatología típica de pulpitis. Una vez que se ha completado la necrosis del tejido vasculonervioso es posible que se presenten signos y síntomas asociados a periodontitis apical o tractos fistulosos. ${ }^{2}$ En algunos casos se presenta discromía coronaria dependiendo del lugar de la reabsorción radicular, su proximidad al tercio cervical y de la presencia de tejido de granulación .6,7 En el examen radiográfico se observa una lesión radiolúcida redondeada bien delimitada con un contorno uniforme que interrumpe la anatomía normal del conducto radicular. ${ }^{8}$

Hargreaves $^{2}$ describe que, si el diente con presencia de reabsorción radicular interna es restaurable y posee un diagnóstico favorable la terapia de elección es el tratamiento del conducto radicular que tiene como objetivos la extirpación del paquete vasculonervioso que sostiene la actividad celular clástica y lograr una desinfección de todo el sistema de conductos.

Sin embargo, la ejecución del retratamiento de una reabsorción radicular interna se ve comprometido debido a la disminución del espesor de las paredes radiculares y de igual manera la complejidad de la limpieza. A continuación, se presenta el manejo de un paciente con una reabsorción radicular interna.

\section{PRESENTACIÓN DEL CASO}

Paciente de sexo femenino de 49 años, ASA I, acude a la consulta con el especialista de endodoncia. Al interrogatorio refiere un cambio de coloración en la corona del incisivo central maxilar izquierdo hace aproximadamente dos años y medio (Figura 1). Durante la anamnesis se logró determinar que la pieza dental no presenta antecedentes de trauma, sin embargo, presenta un tratamiento endodóntico realizado hace 3 años con un diagnóstico inicial desconocido. Al examen clínico presentó múltiples restauraciones y un estado periodontal sano.

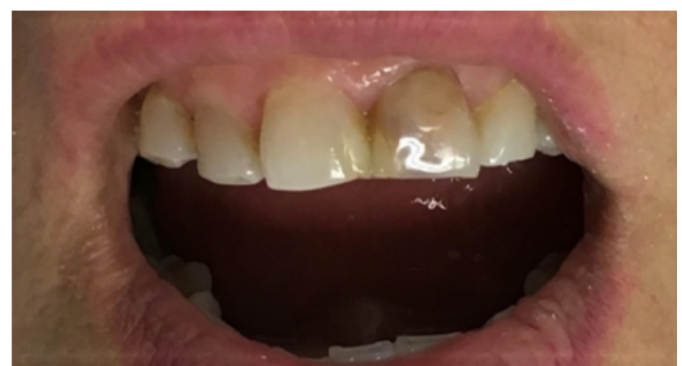

Fig. 1. Diente con coloración coronal alterada

Al examen radiográfico, se reveló la presencia de una reabsorción ósea marginal horizontal, cámara pulpar y conducto radicular obturados; a nivel del tercio medio radicular se observó la presencia de una lesión radiolúcida uniforme en forma de balón, la cual no había sido obturada en toda su dimensión por lo que el material de obturación se encontraba disperso. (Figura 2). Para determinar si la reabsorción radicular era interna y aún no se comunicaba con el periodonto lateral, se procedió a realizar la técnica de tomas radiográficas con diferentes angulaciones (Técnica de Clark),la lesión permaneció en el mismo lugar con respecto al conducto, determinando así que se encontraba únicamente dentro de la luz del canal radicular (Figura 3).Con base a la evaluación clínica y radiográfica, se estableció el diagnóstico de diente tratado endodónticamente con reabsorción radicular interna. El plan fue el retratamiento endodóntico acompañado de un blanqueamiento interno.

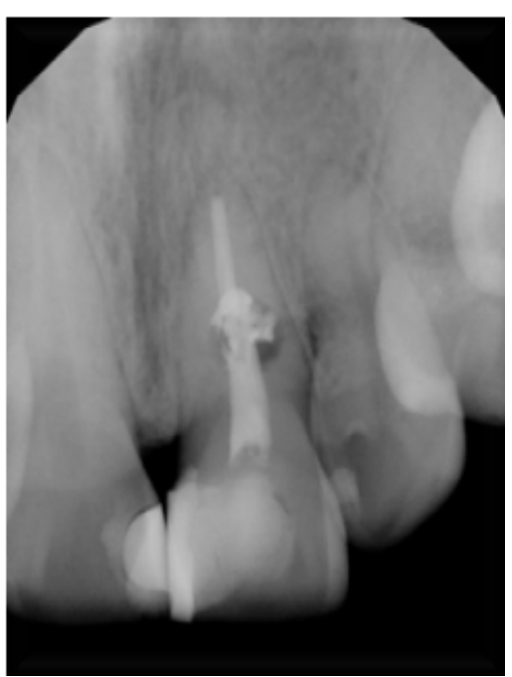

Fig. 2. Radiografía periapical, presencia de reabsorción radicular interna en el tercio medio, obturación deficiente de la lesión y sobre extensión de restauraciones coronales. 


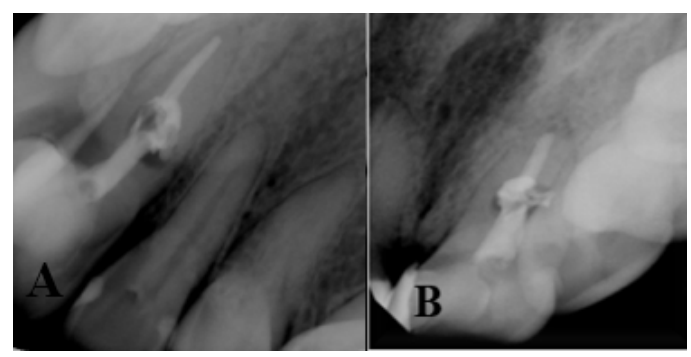

Fig. 3. (A) Radiografía periapical con angulación distal. (B) Radiografía periapical con angulación mesial.

En la primera sesión clínica se realizó el retiro de la restauración de la cara palatina con pieza de alta velocidad y fresa redonda de diamante de grano medio, una vez retirado todo el material de restauración se localizó el conducto y se pudo visualizar el material de obturación colocado previamente, se decidió no realizar una técnica de anestesia para que al momento de retirar el material se tenga toda la sensibilidad posible y no generar desgastes de tejido innecesarios, posterior a esto se colocó aislamiento absoluto del campo operatorio, con dique de goma y arco de Young, dando inicio al retiro de la gutapercha del tercio cervical, en donde se comenzó colocando $0,3 \mathrm{ml}$ de solvente (Eucaliptol/Maquira LTD., Brasil), y con la ayuda de una lima Hedstrom de primera serie \#30 se formó una brecha entre el material y la dentina para el ingreso de la lima y posterior tracción de la gutapercha, esto acompañado de una profusa irrigación con hipoclorito de sodio al $5 \%$, seguido de la comprobación radiográfica del retiro del material y colocación de doble sellado coronal provisional (motita de algodón estéril, cemento de obturación provisional (Fermín) y ionómero de vidrio (Vitrebond) para evitar filtraciones y posible contaminación bacteriana (Figura 4).

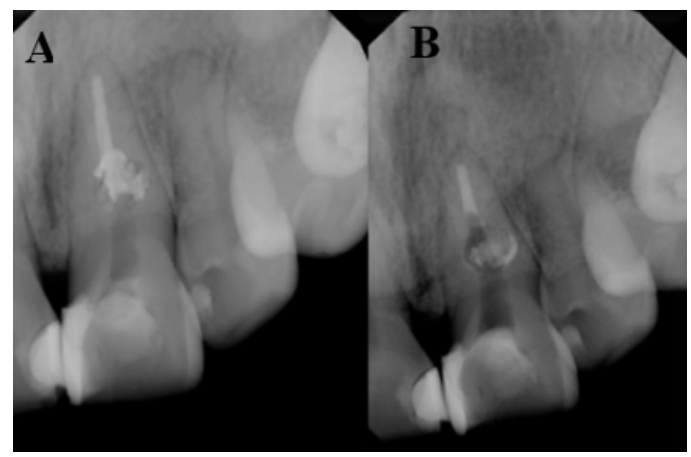

Fig. 4. (A)Desobturación de tercio cervical. (B) Desobturación de lesión de reabsorción radicular interna.

En la segunda sesión, se realizó colocación de aislamiento absoluto, el retiro del material provisional, y se trabajó acompañado de magnificación (Microscopio de pedestal, Zumax), durante el retiro de la gutapercha correspondiente al tercio medio radicular, lugar en donde estaba presente la reabsorción, este procedimiento se realizó con el conducto inundado de hipoclorito de sodio al $5 \%$ y con ayuda de la lima $\mathrm{H} \# 30$,sin solvente, se continuó traccionando los restos de material de obturación, acompañado siempre de un lavado profuso, para retirar todo el material posible y que este no quede más disperso en las paredes de la lesión. Culminado esta sesión se tomó el respectivo control radiográfico (Figura 4).

En la tercera sesión se procedió a colocar el aislamiento absoluto, luego el retiro del provisional,se introdujo $0,2 \mathrm{ml}$ de Eucaliptol en la parte superior del material de relleno restante y se realizó la desobturación de la porción apical con lima Hedstrom manual \#30, apoyados del localizador apical electrónico (Raypex 6, VDW) hasta conseguir la permeabilidad del canal, lo cual permitió obtener la longitud de trabajo; posterior a esto se realizó la comprobación radiográfica del retiro del material intracanal, al observar la imagen, se evidenció la presencia de restos de material de obturación en las paredes de la lesión, mientras que a nivel de tercio cervical y apical ya no se visualizaba remanentes de gutapercha, se colocó medicación intraconducto a base de hidróxido de calcio (Ultracal Xs Ultradent) por 15 días, para controlar la actividad bacteriana y finalmente la colocación de doble sellado coronal provisional (motita de algodón estéril, Fermín y Vitrebond) (Figura 5).

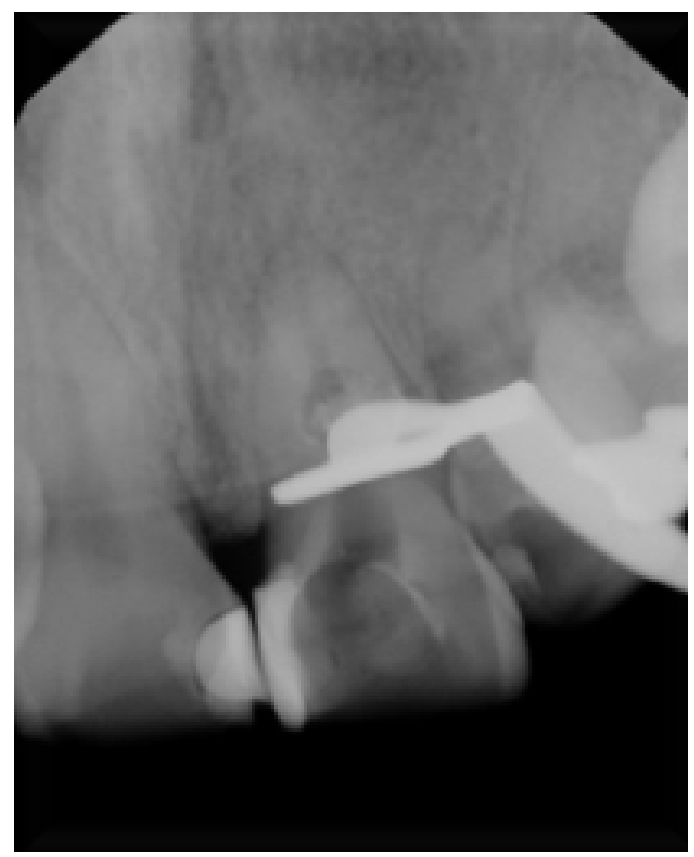

Fig. 5. Desobturación total del conducto y relleno con hidróxido de calcio.

Para la cuarta sesión clínica se procedió a realizar la técnica de anestesia infiltrativa, luego a colocar el aislamiento absoluto seguido del retiro del provisional, posterior a ello 
se repasó la preparación biomecánica del conducto, se retiró la medicación intraconducto con ayuda de irrigación y activación ultrasónica del mismo, (Varios 370, NSK, adaptador E11 y lima \#25), una vez retirada se instrumentó nuevamente el tercio apical con una lima manual K\#35 para conformar el tope apical que recibió el cono maestro, acompañado de irrigación abundante con hipoclorito al 5\%, se consideró oportuno enviar nuevamente a la paciente con medicación intraconducto.

En la quinta sesión de obturación después de la aplicación de anestesia, aislamiento y retiro de provisional se procedió a la remoción de medicación, se limpió las paredes de la lesión con la lima Xp endo Finisher (FKG), que por su forma y movimientos aumenta la posibilidad de tocar casi todas las paredes del canal, sin generar desgaste de las mismas logrando una mejor limpieza del área; posterior a esto se realizó la radiografía de conometría (Figura 6) con un cono de gutapercha \#30/.06, seguido del protocolo de irrigación final, el mismo que corresponde a irrigación profusa con 20 $\mathrm{ml}$ de hipoclorito de sodio al $5 \%$, activación ultrasónica de la irrigación en tres ciclos de 20 segundos seguido de irrigación del canal con EDTA al $17 \%$ durante tres minutos y por último irrigación con suero fisiológico. Luego se procedió al secado del conducto con conos de papel estériles a longitud de trabajo, colocación de cemento en tercio apical (Top Seal) con lima $\mathrm{K} \# 30$, realización del tope apical de gutapercha y su corte con Calamus a 200 grados con punta M, dejando 5 $\mathrm{mm}$ del tercio apical obturado (Figura 6) y para el relleno del área de la lesión, se eligió Biodentine, por ser un material bioactivo que brindará mayor resistencia a la pieza dental, el mismo que se transportó mediante plugger Machtou 1 y 2 en incrementos pequeños para mejor compactación, todo este proceso se realizó con magnificación. (Figura 6).

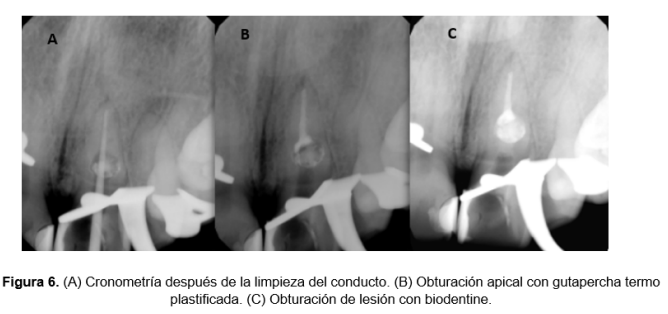

Fig. 6. (A) Conometría después de la limpieza del conducto. (B) Obturación apical con gutapercha termo plastificada. (C) Obturación de lesión con biodentine.

Para la sesión número seis se planificó la realización de blanqueamiento intracameral. Se obtuvo un tono inicial A4 mediante un colorímetro. Mediante un registro fotográfico se estableció el color actual y el color deseado de la pieza dental. Se continúo la cita con el aislamiento absoluto del campo operatorio, seguido de la remoción del provisional coronario, luego se conformó una barrera cervical de ionómero de vidrio y se procedió a colocar el agente aclarante a nivel de la cara palatina de la cavidad de acceso (peróxido de hidrógeno al $35 \%$ ), para sellarlo se colocó una motita de algodón estéril y doble sello provisional, se repitió el mismo proceso por dos ocasiones (séptimo y décimo cuarto día).

A partir del día veintiuno del inicio del aclaramiento se evaluaron los resultados. Se alcanzó una aproximación al tono del diente planificado, observándose una armonía de color junto con los dientes adyacentes; generando un aspecto más estético en la cual la paciente estuvo satisfecha. Posterior a esto se indicó continuar con el tratamiento de rehabilitación oral planificado (Figura 7).

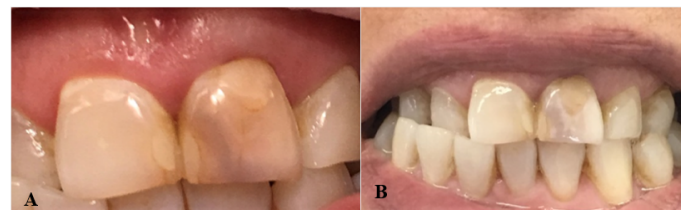

Fig. 7. (A) Pieza 2.1 antes de blanqueamiento interno. (B) Pieza 2.1 después de varias sesiones de blanqueamiento.

\section{DISCUSIÓN}

La reabsorción radicular interna es una condición que se genera a partir de cualquier estímulo sea traumático o infeccioso, que elimina la capa odontoblástica y de predentina, lo cual permite la exposición de la dentina, promoviendo la adherencia de células clásticas a esta estructura. ${ }^{9}$ Por lo tanto la eliminación correcta e íntegra del paquete vasculonervioso, con una obturación tridimensional de la lesión, suprime la posibilidad de progresión. ${ }^{10}$ En este caso, la paciente acudió a la consulta por problemas estéticos y al realizar la radiografía periapical se observó una obturación incompleta y dispersa de la reabsorción, optando así por el retratamiento endodóntico.

La desobturación del conducto en cualquier retratamiento es la base para el éxito, en un estudio realizado por Galiana en el año 2018, ${ }^{11}$ describe que la mejor técnica para la remoción de gutapercha es la combinación de solvente, limas manuales y sistema reciprocante, en el presente reporte se utilizó solvente de gutapercha y limas manuales, pero solo en la zona coronal, ya que el solvente podría enviar restos de gutapercha a las paredes de la lesión, haciendo más difícil su remoción.

La activación ultrasónica del hipoclorito también es un punto importante que considerar, O. I. Uluso en el año $2018^{12}$ concluyó que, la combinación del irrigante $(\mathrm{NaOCl})$ más la activación con XP endo Finisher es un régimen eficaz para eliminar tejido en cavidades simuladas de reabsorciones internas en piezas dentales de un solo conducto.En este caso se utilizó la misma sustancia a mayor concentración acompañada de activación ultrasónica. Se utilizó hidróxido de calcio entre citas para elevar la efectividad desinfectante 
y mantener la alcalinidad dentro del conducto radicular alrededor de dos semanas ${ }^{13,14}$ el mismo que fue retirado con las limas XP endo Finisher de aleación NiTi Max Wire, que poseen alta efectividad en retirar hidróxido de calcio en reabsorciones radiculares internas como lo demostró un estudio realizado por Cangul Keskin en el año $2017^{15}$ en reabsorciones radiculares simuladas, estas limas poseen alta flexibilidad por su cambio de fase martensítica a fase austenítica en contacto con la temperatura corporal lo cual otorga la habilidad de expansión y deformación que permite abarcar las paredes del conducto en tres dimensiones, además tienen alta capacidad de limpieza en la zona apical como lo demuestro un estudio de Rami Hamdan en el mismo año. ${ }^{16}$

En el caso de las reabsorciones radiculares internas no perforantes algunos autores como Nilsson en el año $2013^{17}$ recomiendan el llenado completo del conducto radicular con gutapercha termoplastificada, pero también existen estudios que utilizan técnicas híbridas con biocerámicos para la obturación, GirishUmashett en el año $2015^{18}$ describe la utilización de biodentine en la lesión de reabsorción combinado con gutapercha termoplastificada en la estructura restante del conducto ya que confiere mayor resistencia a la fractura,como lo confirma un estudio in vitro realizado por O”zgu“ rIlke Ulusoy en el año $2016^{19}$ que asegura que el biodentine confiere mayor resistencia a dientes con paredes delgadas de dentina radicular en comparación con otros materiales a base de silicato de calcio.En este caso se optó por la utilización de una técnica híbrida.

La paciente tuvo una evolución correcta y fue dada de alta del área de endodoncia, se recomendó citas recurrentes para controles posteriores a la semana, al mes, a los 6 meses y al año.

\section{CONCLUSIONES}

El diagnóstico oportuno de la presencia de reabsorciones radiculares internas es de vital importancia para su correcto manejo clínico. A pesar de las dificultades en la desobturación, limpieza, visualización y obturación, se logró un sellado completo del defecto. La realización del tope apical fue compleja ya que existió una instrumentación previa que generó complicaciones al momento de la adaptación del cono maestro a la constricción apical. La técnica de obturación que se utilizó fue una técnica híbrida con gutapercha termoplastificada y biodentine, por ser un material bioactivo que brinda un refuerzo a las paredes dentinarias, no genera tinciones y es de fraguado rápido; esta fue la etapa que se consideró de mayor complejidad ya que el corte de la gutapercha a nivel apical a la lesión por su forma irregular no permitió un corte limpio, además del difícil transporte de biodentine al interior de la lesión y el campo de visión directa limitado para la verificación de la obturación tridimensional del área afectada. Este tipo de lesiones requiere de un minucioso plan de tratamiento, un adecuado conocimiento de los instrumentos además de contar con los materiales adecuados y una excelente destreza clínica acompañada de magnificación. 
CONFLICTO DE INTERESES: Los autores no manifiesta ningún conflicto de interés.

\section{Referencias Bibliográficas}

1 Gabor C, Tam E, Shen Y, \& Haapasalo M. Prevalence of internal inflammatory root resorption. Journal of Endodontics. 2012; 38(1): 24-27.

2 Hargreaves KM, Cohen S. Cohen's pathways of the pulp, 11th. ed. St. Louis: Mosby Elsevier; 2016.

3 Ramchandani P, Mellor T. Herpes zoster associated with tooth resorption and periapical lesions. British Journal of Oral and Maxillofacial Surgery. 2007;45(1):71-73.

4 Haapasalo M, \& Endal U. Internal inflammatory root resorption: the unknown resorption of the tooth. Endodontic topics. 2006; 14(1): 60-79.

5 Patel S, Ricucci D, Durak C, Tay F. Internal root resorption: a review. Journal of Endodontics. 2010;36(7):1107-1121.

6 Darcey J, Qualtrough A. Reabsorción: parte 1. Patología, clasificación y etiología. British dental journal. 2013; 214 (9): 439.

7 Thomas P, Krishna Pillai R, Pushparajan Ramakrishnan B, Palani J. An insight into internal resorption. ISRN Dentistry, 2014.

8 Darcey J,Qualtrough A. Root Resorption: Simplifying Diagnosis and Improving Outcomes. Primary dental journal. 2016; 5(2): 36-45.

9 Aidos H, Diogo P,Santos JM. Root Resorption Classifications: A Narrative Review and a Clinical Aid Proposal for Routine Assessment. European Endodontic Journal.2018; 3(3):134-145.

10 Fuss Z, Tsesis I,Lin S. Root resorption-diagnosis, classification and treatment choices based on stimulation factors. Dental Traumatology .2013; 19(4): 175-182.

11 Galiana MB, Gualdoni GM, Langhe D, Montiel NB, Pelaez A. Revisión de desobturación de gutapercha con limas manuales, Xilol y Reciproc. Odontoestomatología. 2018;20(32): 12-23.

12 Ulusoy ÖI, Savur IG, Alaçam T, Çelik B. The effectiveness of various irrigation protocols on organic tissue removal from simulated internal resorption defects. International endodontic journal.2018; 51(9):1030-1036.

13 Sjogren U, Figdor D, Spangbergt L. The antimicrobial effect of calcium hydroxide as a short-terrn intracanal dressing

14 Panzarini SR, Trevisan CL, Brandini DA, Poi WR, Sonoda CK, Luvizuto ER, et al. Intracanal dressing and root canal filling materials in tooth replantation: a literature review. Dental Traumatology.2012; 28(1): 42-48.

15 Keskin C, Sariyilmaz E, Sariyilmaz Ö. Efficacy of XP-endo Finisher file in removing calcium hydroxide from simulated internal resorption cavity. Journal of Endodontics.2017; 43(1): 126-130.

16 Hamdan R, Michetti J, Pinchon D, Diemer F, GeorgelinGurgel M. El XP-Endo Finisher para la eliminación de la pasta de hidróxido de calcio de los conductos radiculares y del tercio apical. Revista de odontología clínica y experimental. 2017;9 (7): e855.

17 Nilsson E, Bonte E, Bayet F, Lasfargues JJ. Management of internal root resorption on permanent teeth. International journal of dentistry, 2013.

18 Umashetty G, Hoshing U, Patil S, Ajgaonkar N. Management of inflammatory internal root resorption with Biodentine and thermoplasticised Gutta-Percha. Case reports in dentistry, 2015.

19 Ulusoy ÖI, Paltun YN. Fracture resistance of roots with simulated internal resorption defects and obturated using different hybrid techniques. Journal of Dental Sciences. 2017;12(2): 121-125.
Recibido: 23 de julio del 2020

Aceptado: 23 de agosto del 2020 